\title{
Wind shear over the Nice Côte d'Azur airport: case studies
}

\author{
A. Boilley ${ }^{1,2, *}$ and J.-F. Mahfouf ${ }^{1}$ \\ ${ }^{1}$ GAME/CNRM (Météo-France/CNRS), UMR3589, 42, Av. G. Coriolis, 31057 Toulouse Cedex 1, France \\ ${ }^{2}$ Degréane-Horizon, 730 rue de l'initiative, 83390 Cuers, France \\ *now at: MINES ParisTech, O.I.E. - Observation Impacts Energy, CS 1020706904 Sophia-Antipolis Cedex, France
}

Correspondence to: J.-F. Mahfouf (jean-francois.mahfouf@meteo.fr)

Received: 22 January 2013 - Published in Nat. Hazards Earth Syst. Sci. Discuss.: 2 April 2013

Revised: 4 July 2013 - Accepted: 23 July 2013 - Published: 11 September 2013

\begin{abstract}
The Nice Côte d'Azur international airport is subject to horizontal low-level wind shears. Detecting and predicting these hazards is a major concern for aircraft security. A measurement campaign took place over the Nice airport in 2009 including 4 anemometers, 1 wind lidar and 1 wind profiler. Two wind shear events were observed during this measurement campaign. Numerical simulations were carried out with Meso-NH in a configuration compatible with near-real time applications to determine the ability of the numerical model to predict these events and to study the meteorological situations generating an horizontal wind shear. A comparison between numerical simulation and the observation dataset is conducted in this paper.
\end{abstract}

\section{Introduction}

Air transport growth over the long term demonstrates a stable trend despite economic stagnation and is expected to increase after an upturn of the economy (Eurocontrol, 2009). In that context, any delay concerning a plane during take off or landing impacts all the airport traffic. Weather conditions account for $15 \%$ among all the causes of delay in Europe. A low-level wind shear (LLW) is a hazardous event that is particularly dangerous in the vicinity of airports where airplanes fly close to the ground at low speed.

A LLW is defined in aeronautics as a wind direction and/or intensity change in space, updraft and downdraft included, that may cause a variation on the plane lift. In case of wind shear encounter during landing, aircrafts initiate a go-around procedure, fly back up to the circuit and prepare for landing once again. This manoeuvre disturbs the entire subsequent approach organization in case of high traffic. Moreover, in case of horizontal wind shears crossing the runways, landing and take off directions are switched. Therefore LLW have important security and economic consequences.

Several measurement campaigns (Wilson et al., 1984) and numerical simulations (Proctor, 1988) have been carried out in the United States since the 1980s and provided a better comprehension of wind shears due to storms, which are called microbursts (Fujita, 1986). The low-level wind shear advisory system (LLWAS, Soffer, 1990) is a consequence of the measurement campaigns. The initial system consisted in the analysis of the difference between the wind observed by a central anemometer and the wind observed by one of five anemometers distributed around the airport. A 15 knots or greater difference triggered an alarm.

Since then, the LLWAS has been updated and can now count several ground and buoy anemometers, a wind lidar, several wind profilers. Since the development in the 1990s of a wind-shear-dedicated radar, LLWAS can be combined with a Terminal Doppler Weather Radar (TDWR, Michelson et al., 1990), to detect wind shear events both on the runways and in altitude. Shun and Chan (2008) present such an updated system applied at the Chek Lap Kok Airport in Hong Kong, China.

Another system, initially based on the Hong Kong airport concept was developed for the Juneau, Alaska airport: the Juneau Airport Wind System. It relies upon a number of sensors (anemometers and wind profilers) installed on high peaks around the airport and on two aircraft wind measurement campaigns. Based on aircraft measurements, an estimation of turbulence has been computed. Then regression coefficients were defined to correlate the computed turbulence intensity with the profiler and anemometer measurements (Politovich et al., 2011). 
Over smaller airports where wind shear occurrence is high, but where the aforementioned systems cannot be installed because of the location of the airport or because of the cost, there is a need of an alternative. The Nice Côte d'Azur airport, located in the south-east of France, is the seat of vertical and horizontal wind shears mostly in winter. Vertical wind shears are due in general to valley breezes that can be measured by ground-based anemometers. Between 10 and 20 horizontal wind shear events, which can be seen as a front of opposed wind directions, are observed each year according to aircraft pilots' reports. These fronts are relatively fine and difficult to detect by conventional ground-based sensors. The relatively dense urban area surrounding the airport and the final approaches over the sea limit the implementation of a complex wind shear detection system. Since the approach routes are located above sea as described in the next section, conventional observations do not provide information in this area. A wind lidar campaign (LIDAR2009) was established at the beginning of 2009 to obtain high-frequency measurements approximately $10 \mathrm{~km}$ around the lidar position. This measurement system has proven its ability to detect wind shears in clear-sky conditions as stated in Shun and Chan (2008).

Though a wind lidar can detect wind shears, the most interesting part for air traffic management would be to predict them. For that reason, a method based on available observations and numerical simulations is considered for the Nice airport. Chan (2012) studies a wind shear event using both observational and numerical data and demonstrates that a numerical model could be able to predict the wind shear event.

The goal of this paper is to study two different horizontal wind shear events over the complex terrain of the Nice region and to determine the numerical model capability to predict these events compared to the observations. Moreover, the complementarity of numerical modelling and observations can provide information about the mechanisms generating a wind shear over the Nice airport. We conducted numerical simulations for two different wind shear situations that took place during LIDAR2009. The comparison presented in the following study focuses on the capability and the lack of the model to predict these wind shear events. When the model was able to reasonably simulate the event, it was used to highlight the key elements leading to the wind shear situation.

We first describe the Nice Côte d'Azur airport location and the instruments installed on the airport during the LIDAR2009 measurement campaign. Two wind shear events have been selected. The meteorological situation for both events is given in Sect. 3. The numerical model Meso-NH (Lafore et al., 1998) as well as its setup and the used diagnostics are described in the beginning of Sect. 4 . The comparison and analysis of the numerical results towards observations are then studied in the following section.

\section{Location and description of the LIDAR2009 measurement campaign}

\subsection{The Nice airport}

The Nice Côte d'Azur International airport is the third busiest French airport by total passenger traffic. Each year 10 million passengers cross the gates of the airport, whereby the theoretical maximum passenger traffic is 13 million. The airport is close to its limit. Due to the dense urban area surrounding the airport, no extensions are possible. A better LLW anticipation is one way to limit their impact on air traffic.

The airport is located in the south-east of France, seven kilometers west from downtown Nice. It was built at the land/sea interface in a bay between two capes: the Cape Ferrat (FC) to the east and the Cap d'Antibes (AC) to the west. The airport runways are approximately $3.5 \mathrm{~km}$ long in the direction $44^{\circ} / 244^{\circ}$. The Var valley runs north-south and opens on to the west of the runways leading to frequent and well predicted vertical wind shear events. The Côte d'Azur is in the lee of the southern Alps where many peaks culminate well above $2500 \mathrm{~m}$, generating discontinued flow over the Nice airport.

A special feature of the Nice airport is the approach routes imposed to aircrafts in clear-sky conditions. In case of easterly wind, good visibility and clouds bottom above $900 \mathrm{~m}$ a.g.l., airplanes have to go round the Cap d'Antibes by south, then fly to the north and turn $90^{\circ}$ to the east to get aligned with runways (dashed line in Fig. 1a). In westerly flow conditions, airplanes cannot take the direct approach because of the relief. They must come from the south-east and turn $90^{\circ}$ to the west to get aligned (dotted line in Fig. 1a). Due to these specific conditions only $25 \%$ flights use the instrument landing system (continuous line in Fig. 1a).

During "good weather" conditions, airplanes do a $90^{\circ}$ bend at $200 \mathrm{~m}$ a.s.l. where LLW can have disastrous effects on airplane trajectory. Due to its location, the airport experiences horizontal and vertical LLW. Most of vertical wind shears are due to mountain breezes in the Var valley. The north breezes spreading a relatively dense air at the mouth of the valley are perpendicular and divert the synoptic flow over the sea. Due to dense air it appears first in the lowest part of the atmosphere and is rapidly detected by local forecasters. On the contrary, horizontal LLW causes are complex and depends on both synoptic and local condition. They are long-lasting events but can cross the airport at different speeds. It has been reported that two opposing wind directions measured on each side of the airport can last several hours, whereas it can cross the platform in a few minutes. The following study describes two types of horizontal LLW generation. 


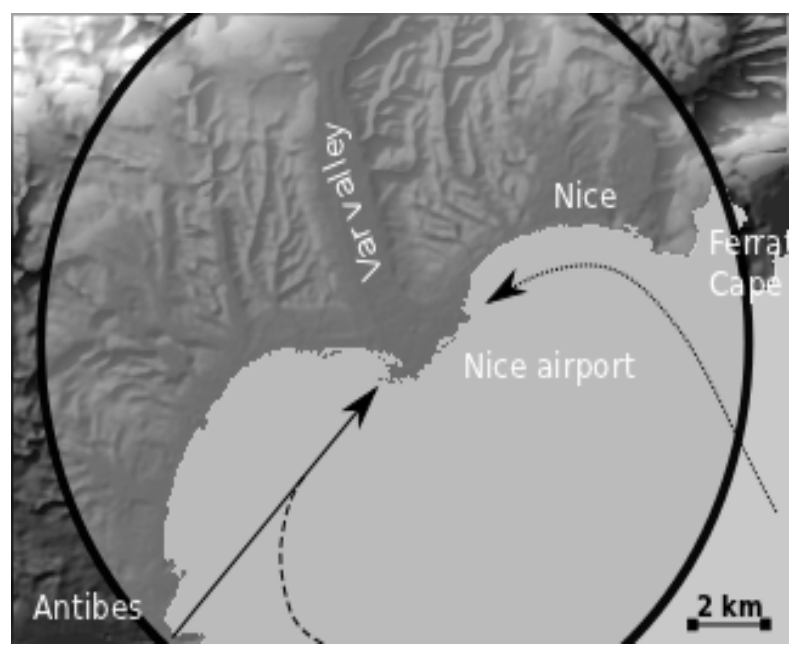

(a)

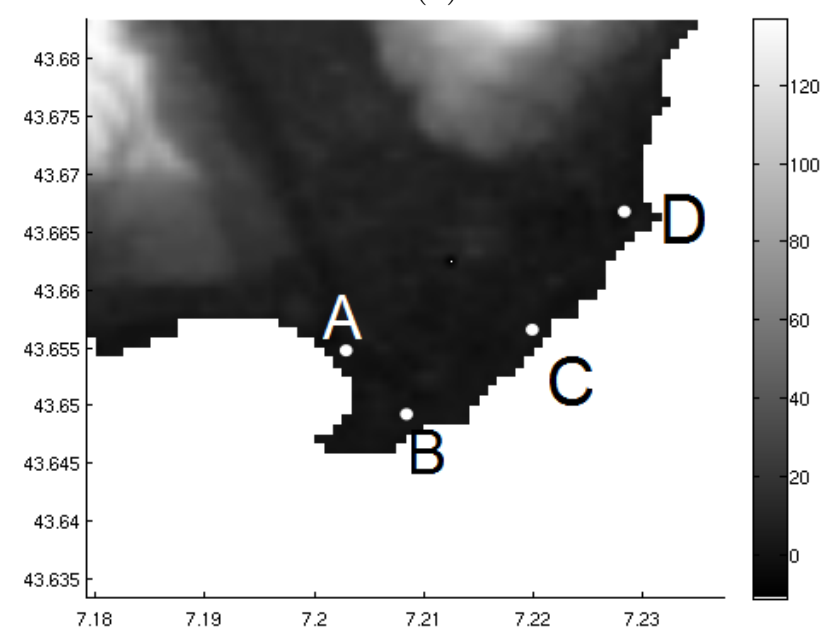

(b)

Fig. 1. Location of the Nice airport on the Shuttle Radar Topography Mission (SRTM) map of the Nice region and airplane routes represented as arrows (a). Approach routes of the airplanes are direct (continuous line), in easterly wind and good visibility condition (dashed line) and in westerly wind conditions (dotted line). The black and shaded circle represents the scan area of the wind lidar. (b) Zoom on the Nice airport SRTM topography and sensor location during the LIDAR2009 measurement campaign. The letters correspond to the different sensors: ultrasonic anemometer and wind profiler (A), west anemometer and wind lidar (B), central anemometer (C), east anemometer (D).

\subsection{LIDAR2009 campaign}

Several sensors are permanently installed on the airport platform (Fig. 1b). Three anemometers are installed at the east (D in Fig. 1b), center (C) and west (B) of the runways and measure the $10 \mathrm{~m}$ wind over the airport. The western anemometer is part of the worldwide surface synoptic network SYNOP. A wind profiler is located at the mouth of the Var valley, $500 \mathrm{~m}$ north-east of the runways (A) and provides vertical wind profile time series up to $5000 \mathrm{~m}$. It is a PCL-1300 DegreaneHorizon wind profiler emitting a signal at $1274 \mathrm{MHz}$. Two different emission times are available, leading to two different configurations: a high-resolution mode providing data from $75 \mathrm{~m}$ to $2000 \mathrm{~m}$ a.g.l. every $75 \mathrm{~m}$, and a low-resolution mode, which provides data from $300 \mathrm{~m}$ to $5000 \mathrm{~m}$ a.g.l. every $150 \mathrm{~m}$. The wind profiler can provide a profile every $2 \mathrm{~min}$.

In the hazardous areas (west and east of the runways over sea) where aircrafts turn, no continuous measurement is made actually. In these conditions, local forecasters estimate that a $3 \mathrm{~km}$ wind measurement range is a minimum to detect hazards in the direct vicinity of the airport and in the runway axis. A wind lidar campaign (LIDAR2009) was set up for a three months period, from January to March 2009, on the Nice airport.

A Lockheed Martin Doppler wind lidar (WindTracer®) was installed by Meteo-France near the eastern anemometer, letter B in Fig. 1b. It emits a near-infrared ( $2 \mu \mathrm{m}$ wavelength) laser beam and computes wind speed from the Doppler shift of aerosol echoes. A laser beam has no secondary lobes improving the spatial resolution through high directivity. In case of low-level clouds or rain, however, the laser beam is strongly attenuated, which drastically reduces the maximal range. The WindTracer® geographical maximal scan area is represented by a gray circle in Fig. 1a. Horizontal scans and elevations can be hemispherical. Indeed, over the Nice airport the wind lidar measurement cycle is made of two hemispherical scans at 2 and $4^{\circ}$ elevation followed by two vertical scans from $2^{\circ}$ to $10^{\circ}$ elevation in the runway directions (44 and $224^{\circ}$ ) and a vertical scan from 1 to $10^{\circ}$ elevation at $335^{\circ}$ azimuth which corresponds to the Var valley direction.

A sonic anemometer was installed near the wind profiler during LIDAR2009. It is located in the Var valley direction $\left(335^{\circ}\right)$ in order to validate data from the lidar. A MétéoFrance internal report demonstrates the good agreement between lidar and standard anemometer measurements with a correlation coefficient of 0.949 even with an altitude difference of $10 \mathrm{~m}$. These results and those obtained by Shun and Chan (2008) demonstrate the reliability of the lidar to detect hazardous events close to the airports on the aircraft route compared to meteorological ground stations. On 24 and on 27 March two wind shear events were observed by the lidar. The significant amount of data obtained during the LIDAR2009 campaign is supplemented by numerical simulations leading to a regional description of the meteorological phenomena.

\section{Synoptic and observational situations}

For each observed wind shear event the description of the meteorological situation is constructed from synoptic observation range to locally observed flow. 


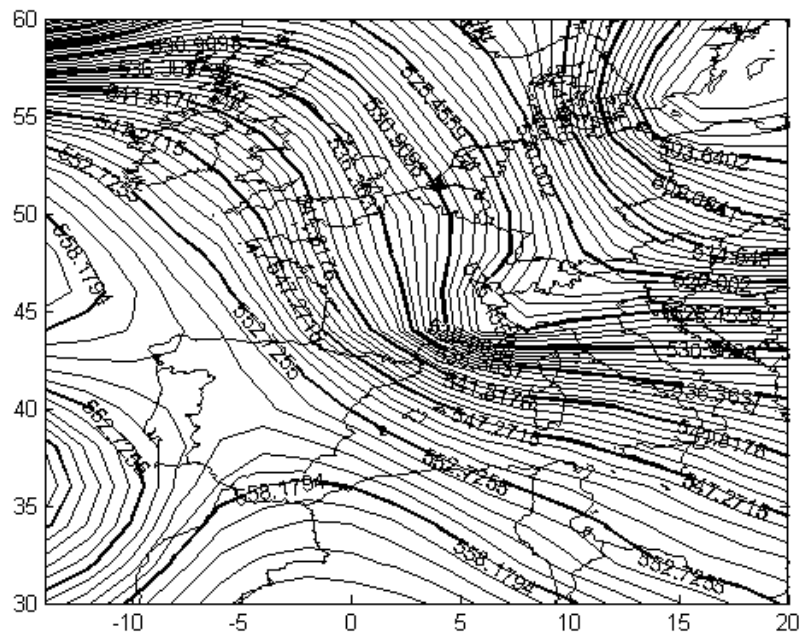

(a)

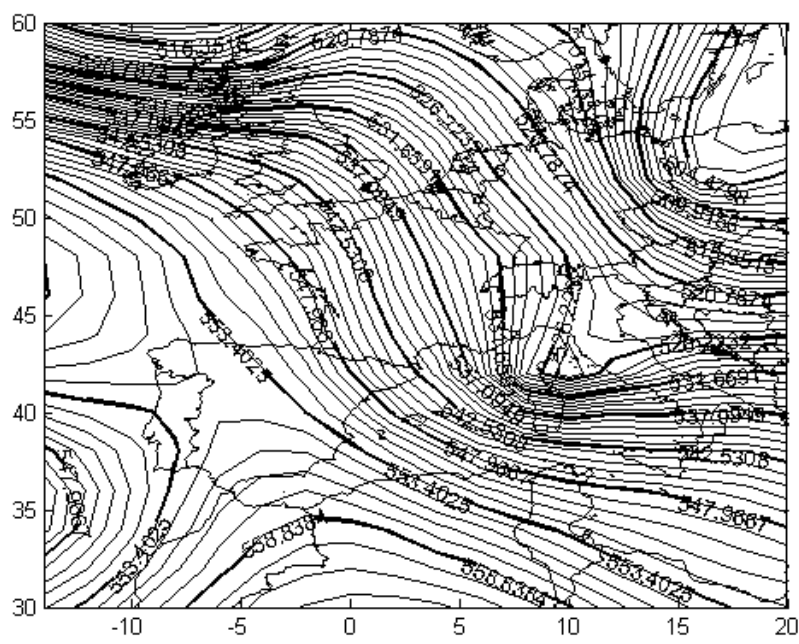

(b)

Fig. 2. $500 \mathrm{hPa}$ geopotential over Europe obtained from ECMWF analysis at 12:00 UTC (a) and 18:00 UTC (b) on the 24 March 2009.

\subsection{March 2009}

On 24 March 2009 at 12:45 UTC, a rather unusual type of wind shear was observed over the Nice airport. It is particular since it occurs in cloudy conditions. Therefore, the Monaco heliport was closed during $1.5 \mathrm{~h}$ and severe turbulence were reported over the Nice bay by pilots.

The $500 \mathrm{hPa}$ geopotential is represented as isolines in Fig. 2 at 12:00 and 18:00 h UTC, from the European Center for Medium-range Weather Forecasts (ECMWF) analysis. A thalweg is present over northern Italy. The north-westerly synoptic flow over France is influenced by the thalweg and turns westerly over the Côte d'Azur. The thalweg position

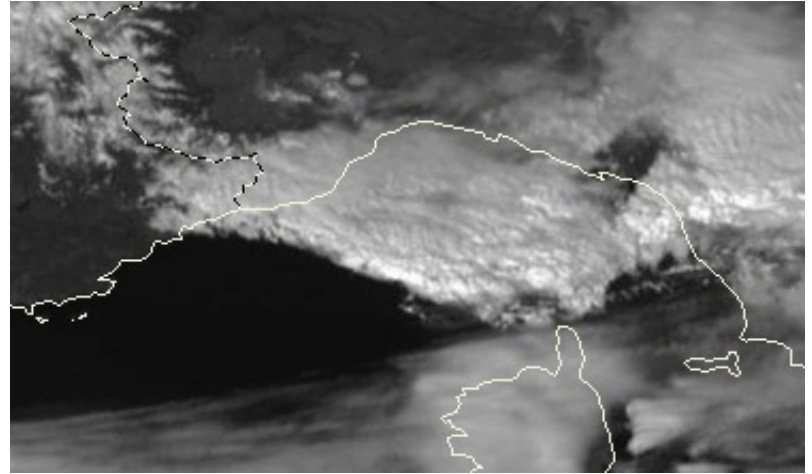

(a)

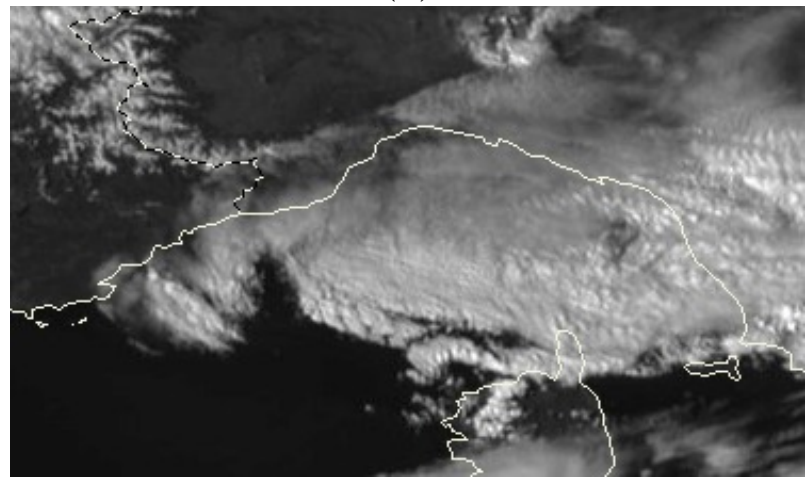

(b)

Fig. 3. Visible images from SEVIRI onboard Meteosat satellite for the 24 March 2009 at 12:30 UTC (a) and 13:00 UTC (b).

moves to the south-west during the next six hours and a northerly flow settles over the Côte d'Azur and northern Italy.

As previously mentioned the event took place during cloudy conditions. The visible images observed by the SEVIRI sensor onboard Meteosat satellite show clouds all over the Genoa gulf to the French-Italian border at 12:30 UTC (Fig. 3a). A cloud front moves towards the west and reaches the Nice region between 12:45 and 13:00 h (Fig. 3a). Its progression to the west is stopped at 14:30 UTC and then the clouds are advected to the south-east (not shown).

Vertical wind profile time series (one profile every two minutes) obtained from the wind profiler are presented in Fig. 4. It demonstrates the rapid wind change over the Nice airport in the first $5000 \mathrm{~m}$ from an easterly to a westerly wind. In Fig. 4b, the westerly wind is observed between 12:45 and 16:30 UTC. Afterwards another change in wind direction occurs and a south-easterly flow is observed in the lowest $400 \mathrm{~m}$. The rapid change coincides with an increasing signal to noise ratio (SNR) between $3000 \mathrm{~m}$ and $5000 \mathrm{~m}$. A rapid increase in the SNR value is due to either a temperature drop or a humidity increase. Since clouds were observed from satellite, the SNR increase is likely related to the cloud front arrival over the Nice airport, generating a rise in humidity and a fall in temperature. A SNR increase is also observed 


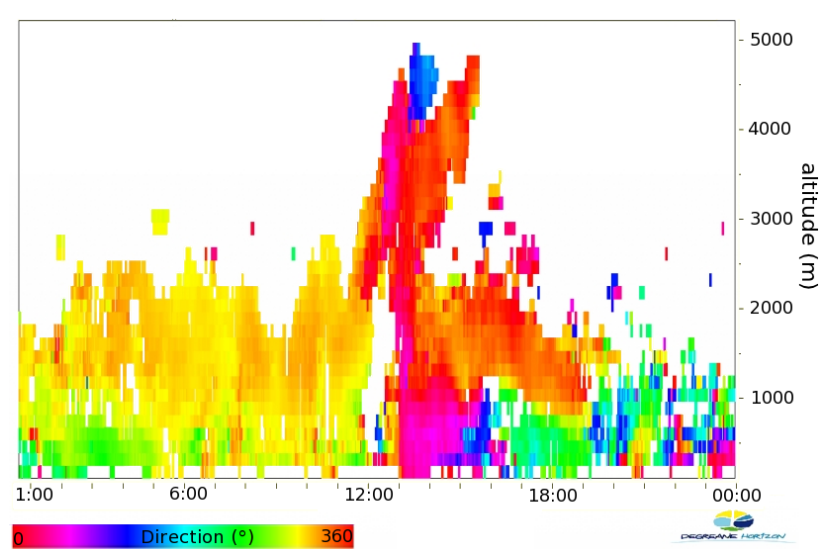

(a)

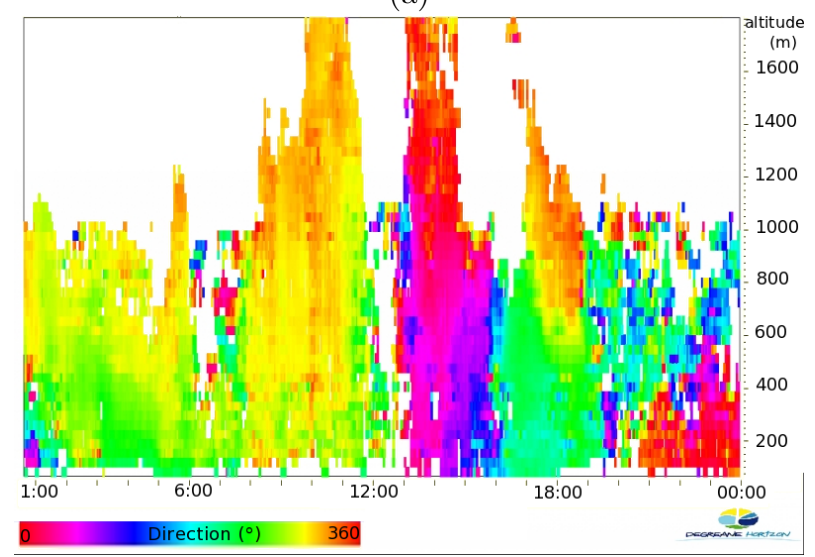

(b)

Fig. 4. Vertical wind directions observed every $2 \mathrm{~min}$ by the wind profiler located at the west of the runways for the 24 March 2009 for the low vertical resolution (a) and for the high vertical resolution (b). Graphs obtained with the Degreane-Horizon signal processing software.

in the lower part of the atmosphere (under $1000 \mathrm{~m}$ ), revealing a change in air mass during the LLW.

The air mass change during the LLW in the lowest part of the atmosphere is confirmed by the ground station measurements. For example, the $2 \mathrm{~m}$ temperature and the $2 \mathrm{~m}$ relative humidity on the Nice airport are respectively $17.8^{\circ} \mathrm{C}$ and $20 \%$ at 12:00 UTC. Two hours later, once the cloud front has reached the Nice airport, the $2 \mathrm{~m}$ temperature has dropped down to $11.9^{\circ} \mathrm{C}$ and the $2 \mathrm{~m}$ relative humidity has reached $50 \%$ (not shown). The wind lidar installed on the runways during the LIDAR2009 field campaign provided $360^{\circ}$ horizontal scans of radial wind every 3 min approximately. The evolution of the local wind structure is well captured. Two scans are presented in Fig. 5 at 12:45 UTC and at 13:00 UTC. At 12:45 UTC the LLW is located at approximately $6 \mathrm{~km}$ of the wind lidar location. 15 min later, a westerly wind blows over the entire airport and the easterly wind is pushed away to the west. The situation remains identical for the two next

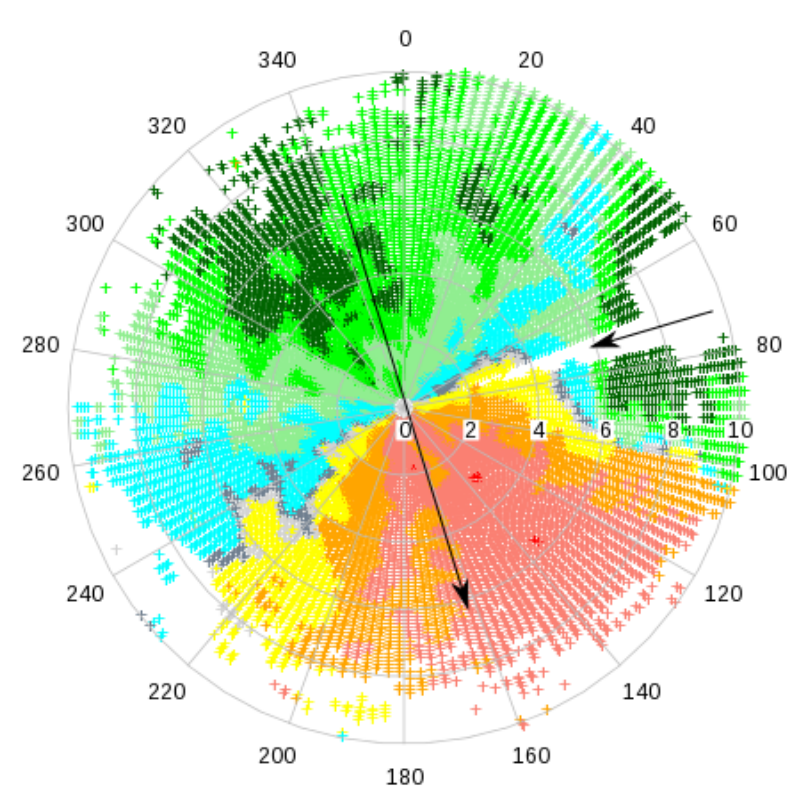

(a)

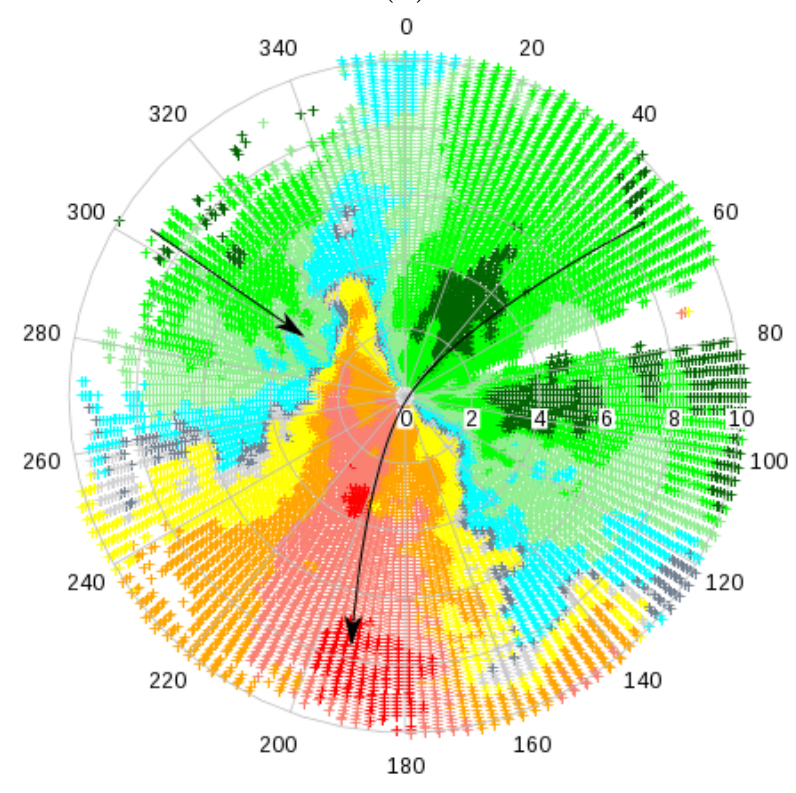

(b)

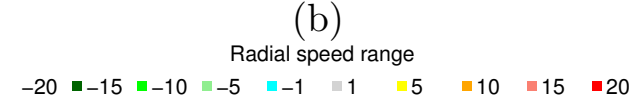

Fig. 5. $4^{\circ}$ elevation wind lidar scans at 12:45 (a) and 13:00 UTC on 24 March. Warm colors mean a radial wind $\left(\mathrm{m} \mathrm{s}^{-1}\right)$ going away from the lidar contrary to cold colors which represent a wind coming to the lidar. Arrows indicate a wind direction interpretation.

hours. Afterwards a continuous wind rotation from west to east by the south is observed.

The wind direction change observed by the different sensors can be related to the thalweg position. As long as the thalweg is located over the Alps, all the northerly synoptic 


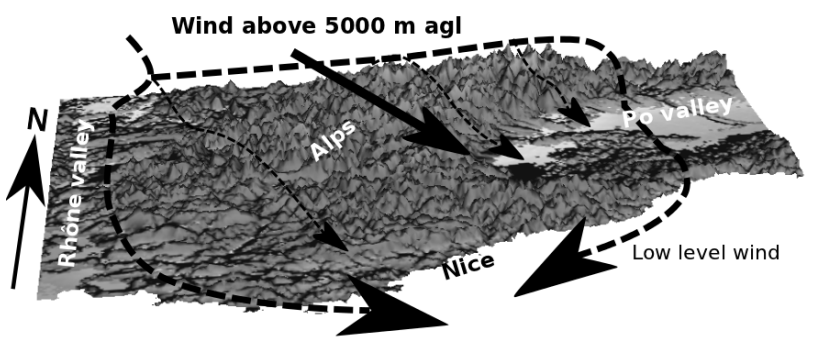

(a)

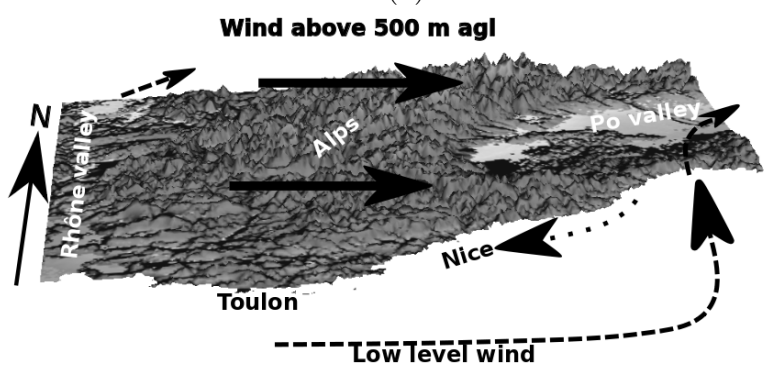

(b)

Fig. 6. Conceptual scheme of the "Alps crossing" case (a) and "vortex case" (b). Plain arrows represents the winds above the boundary layer, dashed and pointed arrows are winds in the boundary layer.

flow rounds the Alps and then is drained off to the west over the Mediterranean Sea. When the thalweg moves from the Alps to the Italian coast, a part of the synoptic flow can cross the Alps and reach the Pô valley. The meeting of both parts of the flow at the French-Italian border generates a cloud front observed by satellite. The continuous move of the thalweg to the south forces the flow crossing the Alps to get an easterly direction along the coast when the thalweg is located just above the Genoa gulf. This easterly flow is opposed to the westerly flow coming from the Rhône valley and generates a wind shear over the Mediterranean Sea as presented in the conceptual scheme in Fig. 6a. This case will be called a "Crossing the Alps" case.

\subsection{March 2009}

On 27 March 2009, an horizontal wind shear was observed between 07:30 and 08:00 UTC by the lidar and induced a switch of the approach procedure directions by the air traffic control.

A westerly wind blows all day long over western central Europe generated by a low geopotential region over northern Ireland and a high geopotential region over the Canary Islands (Fig. 7). In the lower layer, the Massif Central (center of France) and the Alpine range split the westerly flow into two parts. The one rounding the mountains to the south, reinforced by the wind blowing out of the Rhône valley, is at the origin of the wind shear. It reaches the Mediterranean Sea and blows along the French coast to the Italian border. The shape of the extreme south of the Alps and of the Genoa

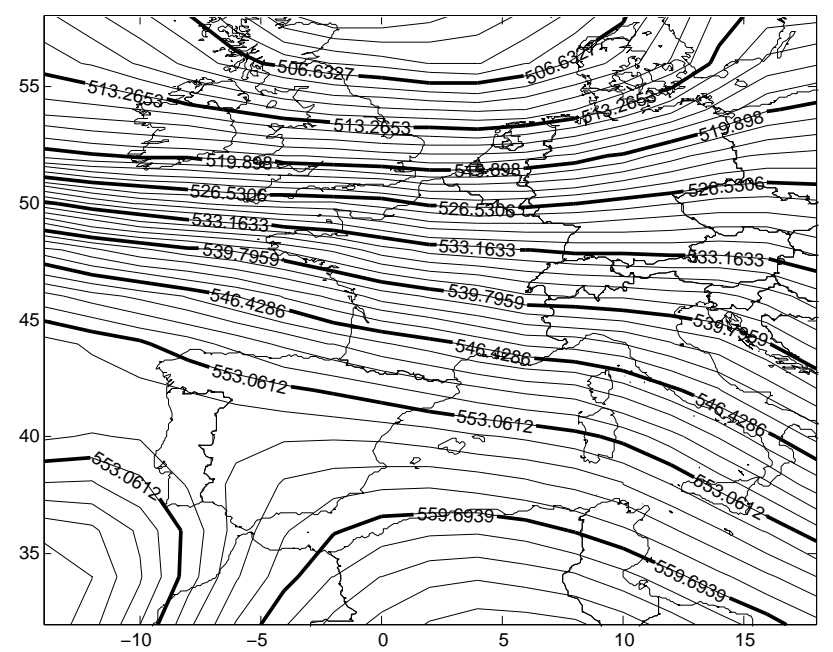

Fig. 7. $500 \mathrm{hPa}$ geopotential over Europe obtained from ECMWF analysis at 06:00 UTC on the 27 March 2009.

gulf conduct to a lee vortex in the Genoa gulf similar to the lee vortices simulated in Ólafsson and Bougeault (1996) past an elliptic mountain ridge. The vortex is initially contained in the Gulf of Genoa. The synoptic westerly wind reinforcement after sunrise induces a growth of the vortex. Its extent reaches the Nice airport where a horizontal LLW is observed at 07:45 UTC. This case will be called "vortex case" in the following and a conceptual scheme of this event is presented in Fig. 6b.

Vertically, the wind flow over the Nice airport can be separated in two parts clearly visible on the wind profiler time series as well as on the vertical wind profiles given by the AMDAR message at 08:37 (presented in Fig. 8). Above $500 \mathrm{~m}$, the strong westerly wind flow is relatively constant all day long. Under this altitude the flow varies. For example, at the time of the AMDAR message, the LLW had already happened on the Nice airport and only the first $500 \mathrm{~m}$ of the atmosphere were concerned.

The SYNOP network provides a regional point of view of the $10 \mathrm{~m}$ wind. A westerly wind has been observed all day long by the stations located at the extreme south of the Alpine range (Toulon region cf. Fig. 6b) whereas the stations in the lee of the Alps demonstrate a perturbed wind. Indeed, a northerly wind, typical of valley breezes, is observed by most French coastal and valley stations in the early morning. In one hour, between 07:00 and 08:00, the wind direction changes from a northerly to an easterly wind for all the coastal stations, whereas northern inland stations still observe an easterly $10 \mathrm{~m}$ wind. The wind direction is only observed in the boundary layer in the coastal area.

The $2 \mathrm{~m}$ temperature also rapidly and simultaneously changes during this event. It ranges between 6 and $10^{\circ} \mathrm{C}$ before 07:00 all along the coast. After sunrise, the temperature goes up and reaches $11.8^{\circ} \mathrm{C}$ at the Nice airport at 10:00. At 


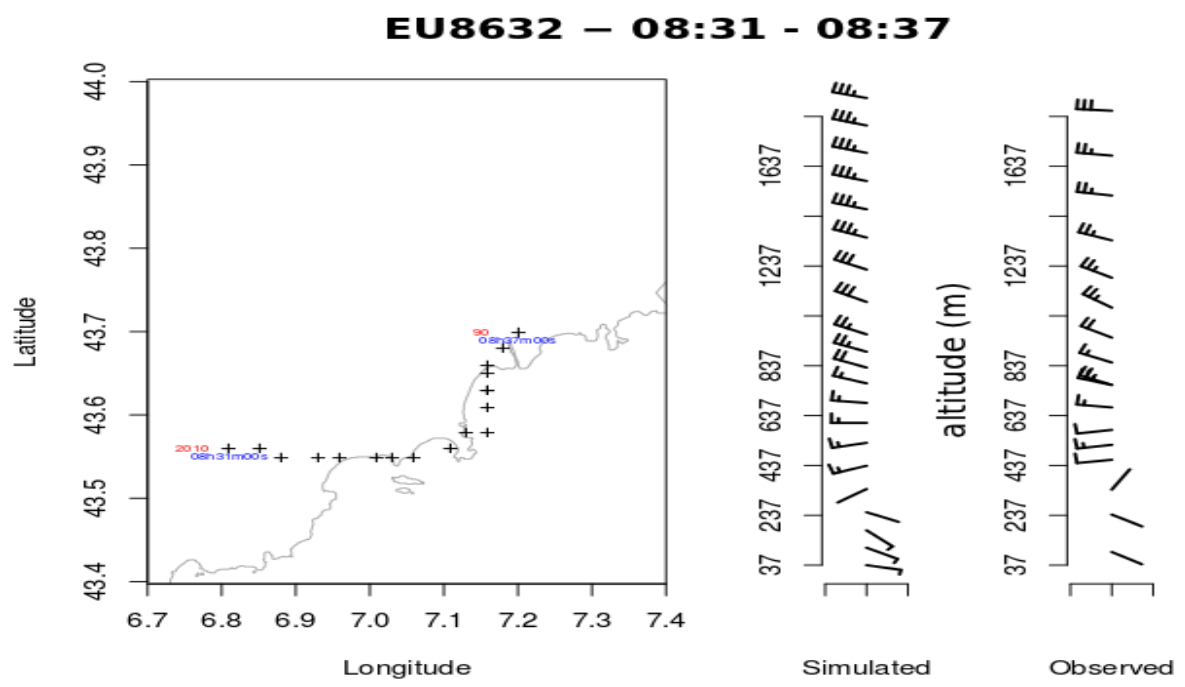

Fig. 8. Graphical representation of the AMDAR message recorded at 08:37 UTC on 27 March at the Nice airport. The "+" represents the geographical position of the plane and the altitude and time of observation are given by red and blue values, respectively. The simulated and observed wind barbs (kt) on the right correspond to the wind at each "+" point.

the same time, the observed $2 \mathrm{~m}$ temperature at the extreme south of the Alps is $22^{\circ} \mathrm{C}$. This temperature difference remains constant until the end of the day, showing two contrasted air masses. A cold air mass associated with an easterly wind settles along the Côte d'Azur coast and a warm air mass associated with a westerly wind is present away from the coasts. It can be noticed that the wind direction in the warm air mass is similar to the synoptic flow in altitude.

According to the previous statements and in absence of observations over the sea, we speculate that in the early morning the valley breezes drain a cold air to the sea, which is advected by the westerly wind to the Genoa gulf. The accumulated cold air combined with the shape of the Alps and the Apennines range generate a stable low level air mass as high as the mean Apennines (approx. $500 \mathrm{~m}$ ). In these conditions, the synoptic westerly wind needs to circle around this stable area leading to the rotation of the cold air mass in the Genoa gulf. The enhancement of the westerly wind in the morning induces a blocking of the cold air against the Alps. This increases its horizontal extent to the Nice airport and the associated easterly wind along the coast. This configuration explains the observed difference in $2 \mathrm{~m}$ temperature.

Over the Nice airport, the four anemometers associated with the high-frequency vertical and horizontal wind lidar scans confirm the previously described morning flow above the Nice airport and show a more complex local flow than a single rapid wind change.

In the morning, the three western anemometers record a northerly wind due to the valley breeze (Fig. 9). The eastern anemometer time series exhibit a weak north-westerly wind as the breeze is influenced by the westerly low level wind blowing over the sea. The valley breeze wind direction is already modified $2 \mathrm{~km}$ away from the Var valley mouth (distance separating the central and eastern anemometers). At 08:00 UTC, the wind speed decreases to less than $0.5 \mathrm{~m} \mathrm{~s}^{-1}$ over the entire airport platform. A first wind direction change from north to south-east occurs in $15 \mathrm{~min}$. The wind speed and direction remain stable until 09:30 when a second wind shear happens. From that time, the wind blows from the east and the intensity increases rapidly: approx. $4 \mathrm{~m} \mathrm{~s}^{-1}$ in $1 \mathrm{~h}$. The sonic anemometer constantly overestimates the wind speed (Fig. 9). The same overestimation is made with the time series for the 24 March LLW event. Between 08:30 and 09:30 a transitional period is noticed and the high temporal frequency lidar scans provide supplementary information. On the $2^{\circ}$ elevation scan presented in Fig. 10a the southeasterly flow is established on the airport, whereas $5 \mathrm{~km}$ to the south (corresponding to an altitude of $170 \mathrm{~m}$ a.s.l.) a westerly flow is observed. These distances and altitudes are similar to the distance between the airport and the extreme south of the Cap d'Antibes and the highest altitude of the Cape Ferrat. The wind observed at the airport in the lower layer of the atmosphere is a local wind circulation in the lee of the Cap d'Antibes. This local "whirlwind" responsible for the first wind direction change is observed when the valley breeze ends. It remains unchanged until the eastern wind blows away this local effect at 09:30. At this time (Fig. 10b), the south-easterly wind is still observed on the airport platform but an easterly wind (blue part north of the blind zone) appears. This easterly wind corresponds to the Genoa gulf vortex. It blocks the westerly flow observed over the sea at 08:30 as observed on the lidar scan and propagates towards the west, generating the second wind direction change between 09:30 and 10:00. 


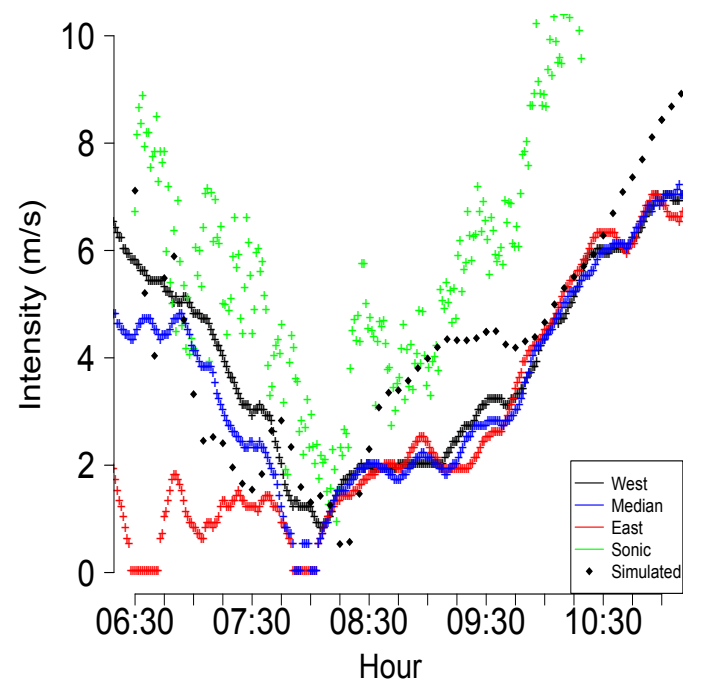

(a)

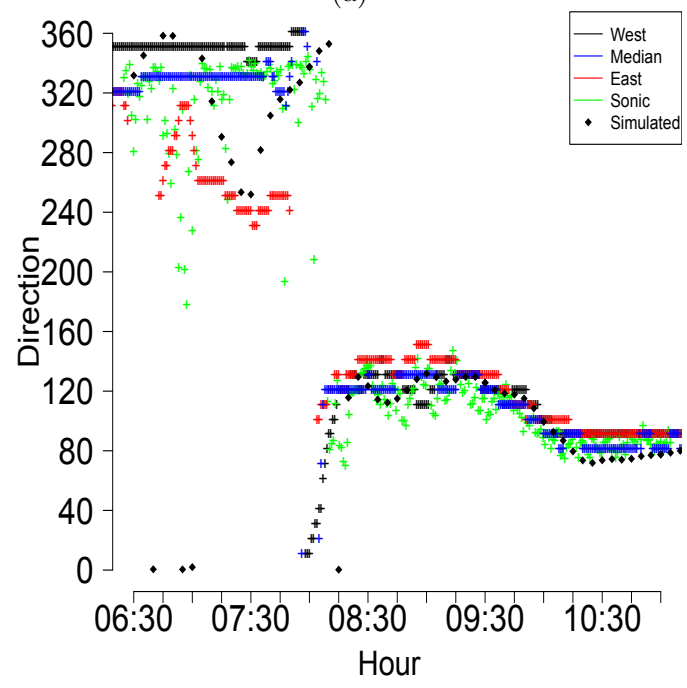

(b)

Fig. 9. Wind intensity (a) and wind direction (b) observed (colored + ) by the four anemometers installed on the runways during the LIDAR2009 experiment and simulated (black dots) over the Nice airport for the 27 March 2009.

The LLW vortex case observed on the 27 th starts with the advection of a cold air mass over the sea due to local valley breezes. The cold air is then advected to the Genoa gulf where it accumulates in the boundary layer. This stable air mass deviates the westerly synoptic flow and starts spinning generating a local vortex which extends in the next hours. In the mean time, a smaller vortex is generated in the Bay of Nice, sparking off a local wind flow.

\section{Numerical modeling}

In this section comparisons between available observations and numerical simulations are carried out. The ability of the

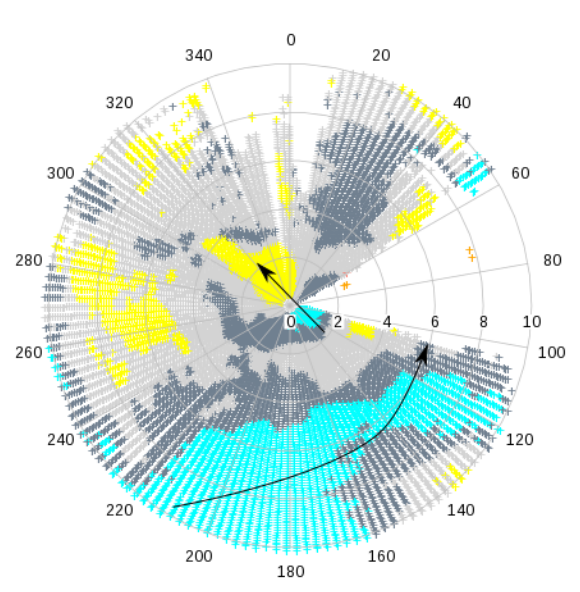

(a)

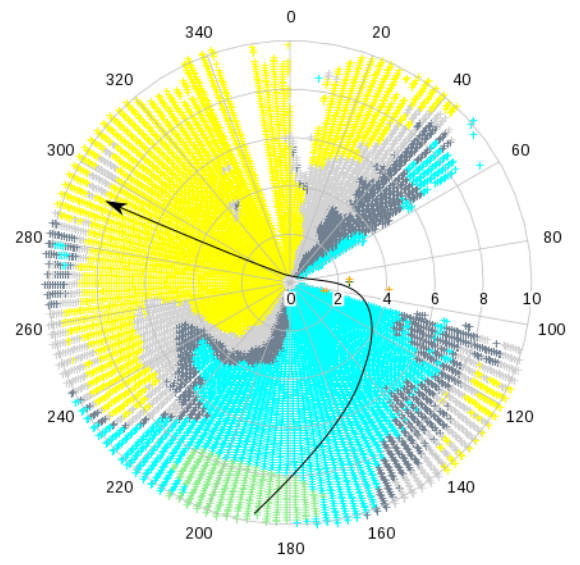

(b)

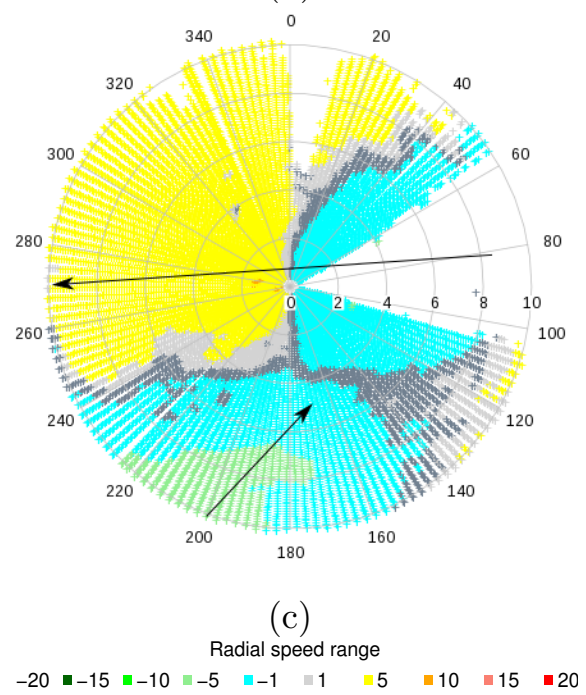

Fig. 10. $2^{\circ}$ elevation wind lidar scans at 08:00 (a), 08:30 (b), 09:30 (c) and 10:00 UTC (d) on 27 March. Warm colors mean a radial wind $\left(\mathrm{m} \mathrm{s}^{-1}\right)$ going away from the lidar contrary to cold colors, which represent a wind coming to the lidar. Arrows indicate a wind direction interpretation. 


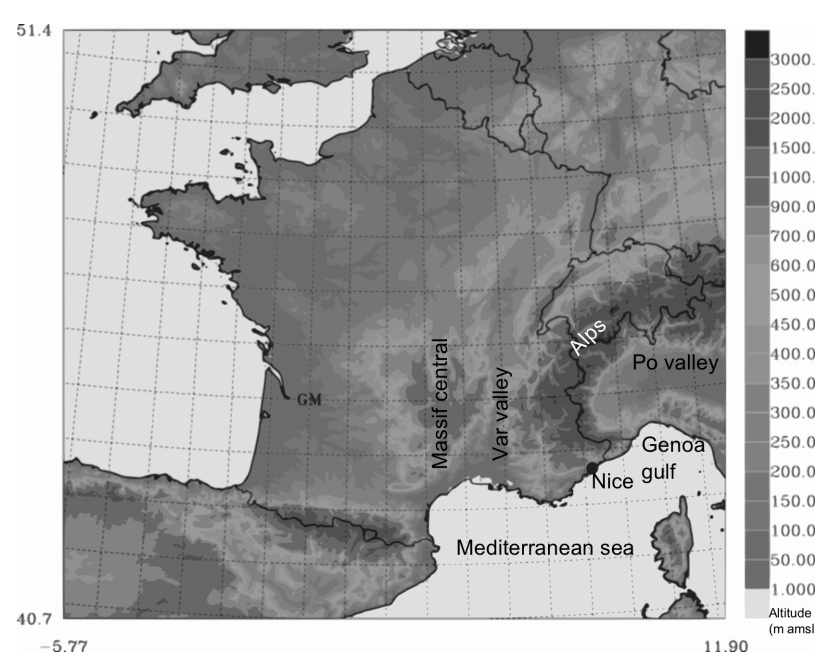

Fig. 11. Simulation grid domain and name of locations of interest.

model to simulate LLW is evaluated for both previously described hazardous events against the measurement dataset. The gridded information from a meteorological model is useful to complement the observational network in order to provide a consistent picture of the event. A better understanding of the meteorological conditions leading to wind shear events in the complex orography of the Nice Côte d'Azur airport region is a first step towards improved numerical forecasts.

\subsection{Numerical model setup}

The numerical simulations are performed with the nonhydrostatic Meso-NH model (Lafore et al., 1998), which is based on the anelastic approximation with purely explicit second order accurate spatial and temporal discretizations. The prognostic variables are the three wind components, dry potential temperature, the mixing ratio of six different classes of water, and turbulent kinetic energy. The model contains a comprehensive set of physical parametrization schemes to describe sub-grid-scale processes. The terrain-following vertical coordinate is based on the Gal-Chen and Sommerville (1975) parameterization. The SURFEX model is an externalized surface model run in parallel with Meso-NH. It contains several schemes to model fluxes over different surface types such as water surface (Belamari, 2005), urban areas (Masson, 2000) or vegetation (Noilhan and Planton, 1989).

Turbulence equations for both simulations are closed using a 1.5 order scheme, resolving only vertical exchanges with the Bougeault and Lacarrère (1989) mixing length formulation. The ECMWF radiation code is implemented in MesoNH. It uses the RRTM scheme (Mlawer et al., 1997) for longwave and the scheme described by Fouquart and Bonnel (1980) for shortwave radiation. Since clouds were observed during one LLW event, a complete 6-class, one-moment bulk microphysics scheme is used (ICE3; Pinty and Jabouille,
1998). These radiation schemes are the same as those in the operational AROME model (Seity et al., 2011) to be in a configuration that could be setup for near real-time applications.

The simulation grid domain is presented in Fig. 11a. The horizontal resolution is $2.5 \mathrm{~km}$, the domain contains $540 \times$ 480 points horizontally and 60 vertical levels from $10 \mathrm{~m}$ to $36 \mathrm{~km}$ high, including 23 levels below $2000 \mathrm{~m}$. The orography is obtained from the GTOPO30 database, which has a $30^{\prime \prime}$ of arc angle resolution, i.e. approximately $1 \mathrm{~km}$. Simulations start from the LLW closest analysis time. Initial conditions are obtained from operational analyses of the AROME model at $2.5 \mathrm{~km}$ resolution. The boundary conditions are obtained from hourly forecasts from the coarser scale $(9.5 \mathrm{~km})$ limited area model ALADIN (Bubnova et al., 1995) run over a wider domain. ALADIN includes a 3D-Var data assimilation system (Fischer et al., 2005). Each simulation experiment lasts $6 \mathrm{~h}$ and outputs from Meso-NH are written every $0.5 \mathrm{~h}$. These are the best physical and dynamical configurations of a numerical model that could be made available in real time to forecasters for issuing warnings over the Nice airport.

A nested domain at $500 \mathrm{~m}$ resolution centered on the Nice airport composed of $360 \times 200$ points has been run for both events. The use of the orographic database from the Shuttle Radar Topography Mission (SRTM) at 30" resolution induces a better representation of the orography and consequently of the topographic effects such as valley breezes or hill effect as demonstrated in Gohm et al. (2004) for example. This improvement would be very useful for vertical wind shears generated by valley breezes for example. For the horizontal wind shear simulations presented in the following, the spatial extent of the wind shear front was improved due to point density compared to a $2.5 \mathrm{~km}$ resolution grid. However, the location in space and time of the wind shear was not modified by the higher resolution. The relatively small size of the domain and the weak improvement related to resolution increase demonstrate that both LLWs are mainly driven by synoptic phenomena. For these reasons the high-resolution domain did not allow for the study of the synoptic phenomena generating the wind shears. The results from this domain will not be presented in the following.

Meso-NH includes a set of diagnostics providing for example, lagrangian tracers, chemical and aerosol variables, aircraft or balloon trajectories, radar and lidar simulator. In the following the lidar simulator is used to compare numerical simulations to wind lidar observations. The simulator is based on the radar simulator (Caumont et al., 2006) in which the secondary lobes effect is not taken into account and the range is reduced to $10 \mathrm{~km}$ due to laser wavelength. Output resolution may be increased to obtain a similar resolution to the observations. Simulated lidar scans in the following study have a $1 \mathrm{~km}$ horizontal resolution and are obtained from $2.5 \mathrm{~km}$ resolution simulations outputs. 


\subsection{March 2009}

The numerical simulation for 24 March starts at 12:00 UTC using an AROME analysis. In the meteorological situation description the importance of a thalweg location was demonstrated. The position of this thalweg is not well reproduced in the numerical model. Indeed, it has moved too far east and too rapidly in the simulation. On the contrary it does not move enough to the south. At the end of the simulation, the local minimum located north of Corsica in the ECMWF analysis (cf. Fig. 2) is located over northern Italy in the numerical simulation (not shown). Consequently, the streamline curvature simulated by Meso-NH is less pronounced at 18:00 UTC in the Genoa gulf than in the re-analysis as presented in Fig. 12. Therefore, the flow that crosses the Alps is not constrained enough to the west and may not reach Nice close to the ground. Only when the local minimum is located over Genoa in the simulation, does the flow distortion get strong enough to generate a LLW over the Nice airport; the rapid displacement to the east, however, leads to a rapid disappearance of the curvature.

The cloud cover was found to be a useful tracer of the wind shear position in the meteorological description part. Both infrared $(10.8 \mu \mathrm{m})$ Meteosat images and their simulated equivalent are presented in Fig. 13. The simulated cloud cover is underestimated overall in the simulation domain and particularly over the Alps. Indeed, after $1 \mathrm{~h}$ of simulation, no clouds are simulated in the Nice area, whereas the cloud front already reaches Nice in the Meteosat images. After $2.5 \mathrm{~h}$ of simulation, the cloud front reaches the airport. Afterward, observation and simulation similarly move the clouds toward the sea.

The lack of clouds in the numerical simulation induces a less pronounced air mass contrast in the lower layer over the coast. The $2 \mathrm{~m}$ temperature and relative humidity change observed is not as pronounced in the simulation result. The cold and humid air mass is shifted to the south over the sea and does not stay close to the coast. This position is related to the thalweg east displacement, which does not constrain the flux to go to the west along the coast. The Italian side of the Alpine range acts as an obstacle for the cold and humid front, which does not reach the Nice airport without the additional constraint of the thalweg.

As a consequence of those misrepresentations, the LLW occurs $2 \mathrm{~h}$ late over the Nice airport as presented on the simulated $10 \mathrm{~m}$ wind time series (Fig. 14). The LLW is simulated at 14:45 whereas all four anemometers record a rapid wind change at 12:45. However, the simulated time series of the wind direction before and after the LLW is similar to the observed wind direction. The general meteorological circulation is well simulated but the bad location of the thalweg generates a shift in space and time of the LLW. The simulated wind speed is overestimated all day long. It is similar to the synoptic wind observed in the Toulon region. Once again, this can be related to the weaker constraint imposed by

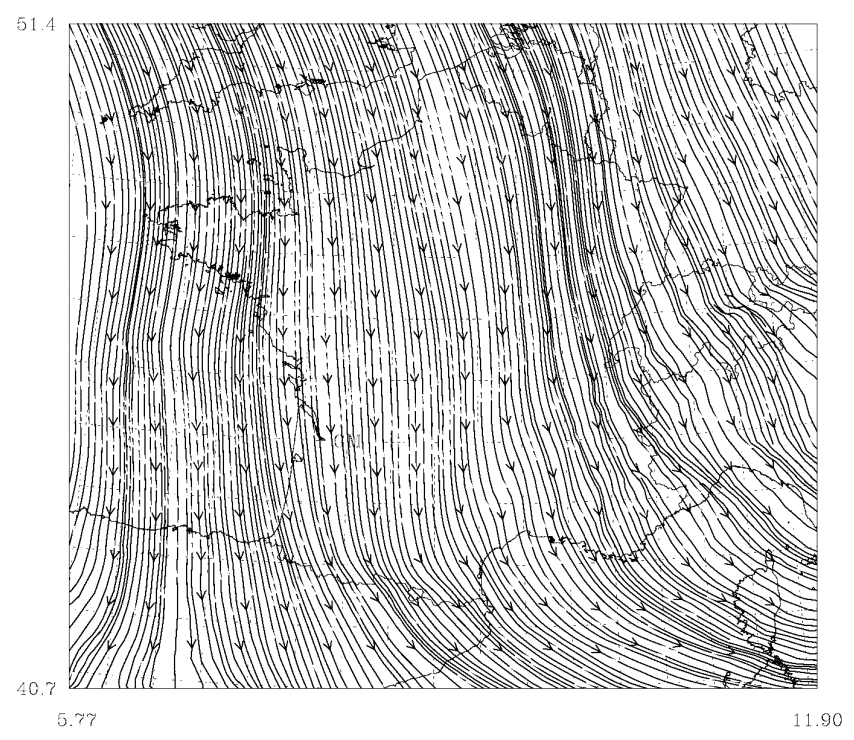

Fig. 12. Stream field at 18:00 UTC simulated by Meso-NH at the nearest model level from $500 \mathrm{hPa}$.

the thalweg: the westerly synoptic flow is established further east than in the observation. The time variation is however similar to the observed wind speed. The low wind speed at 14:30 is not simulated long enough due to the rapid displacement of the thalweg to the east in the simulation as described previously.

The general circulation is similar and the cause of the forecasted LLW is the same as that of the observed LLW. Therefore, the simulated wind structure near the airport area, but shifted $2 \mathrm{~h}$ before, can be compared to the lidar scans. Figure 15 exhibits a wind lidar scan at 13:00 at $4^{\circ}$ elevation and its $2 \mathrm{~h}$ later simulated equivalent (15:00) at $1 \mathrm{~km}$ resolution. The wind structure is clearly similar, with an easterly wind pushing away the previously installed westerly wind. There is a slight difference in the wind direction for the esterly wind: it comes from the east in the simulation whereas it comes from the north-east on the lidar scan. This difference is coherent with the misplacement of the cold and humid cloud front position in the simulation.

The 24 March 2009 LLW case described as a "crossing the Alps" case is related to a thalweg location. The mesoscale simulation introduces a bias in the thalweg position during the simulation. It leads to a $2 \mathrm{~h}$-late LLW prediction, overestimation of the wind speed and an underestimation of the cloud cover. However, the wind structure is similar to the structure observed by the wind lidar over the Nice airport. In that case, the use of a high-resolution numerical model can warn the air traffic management about the possible occurrence of a LLW over the airport. However, in the configuration presented in this paper the time and duration of the hazard cannot be completely anticipated. It could be profitable in that case to run a model at higher resolution and 
(a) 13:00
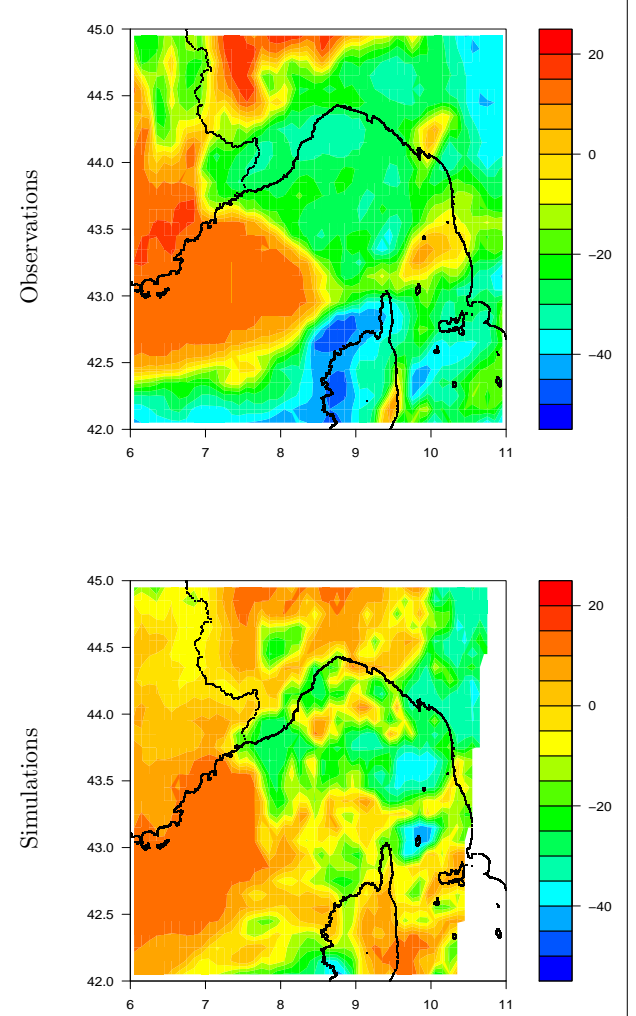

(b) $14: 30$
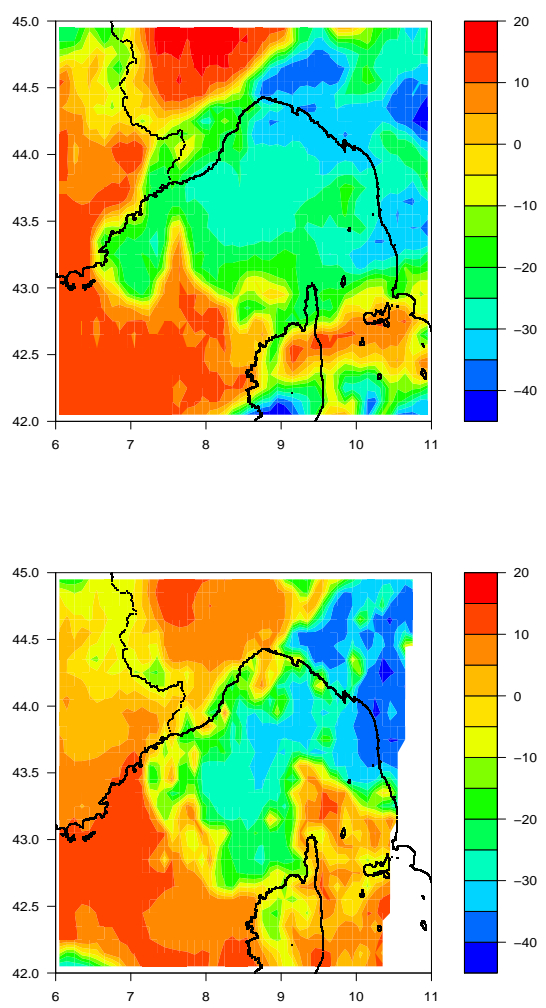

Fig. 13. $10.8 \mu \mathrm{m}$ infrared brightness temperature $\left({ }^{\circ} \mathrm{C}\right)$ observed by SEVIRI onboard Meteosat satellite and simulated by Meso-NH at $2.5 \mathrm{~km}$ resolution computed using the radiative transfer model RTTOV at 13:00 (a) and 14:30 UTC (b).

assimilate local high-resolution data (wind lidar for example) and/or high temporal frequency data (wind profiler) to study the impact on the LLW position.

\subsection{March 2009}

The numerical simulation of the 27 March 2009 LLW event is initialized at 06:00 UTC with an AROME analysis. It is coupled hourly with ALADIN forecasts and runs until 12:00. In that case, the LLW should occur $1.5 \mathrm{~h}$ after starting the simulation.

The streamlines at the nearest model level from $500 \mathrm{hPa}$ in Meso-NH are similar to the geopotential presented in the meteorological description (Fig. 7) and are maintained all along the simulation. The geopotential gradient is strong over the Mediterranean Sea, south of France, inducing a strong wind over this area. In the boundary layer this strong wind is channeled and even more reinforced between the Massif Central and the Pyrenean range (not shown). The general circulation is very similar to the ECMWF analysis.

On the vertical direction, the comparison between the simulation and the wind profiler (not shown) and the AMDAR reports (Fig. 8) shows an underestimation of the vertical extension of the LLW layer as well as an overestimation of the wind speed at all altitudes even in the lower layer.

The same conclusion arises when examining the $10 \mathrm{~m}$ wind time series over the Nice airport presented in Fig. 9. The wind intensity is slightly overestimated, particularly during the hour following the LLW. This hour corresponds to the transition period when a vortex takes place locally in the lee of the Cap d'Antibes. However, during this hour and until the end of the simulation period, the wind direction fits the observations even during the second wind direction change at 10:00 UTC. The wind direction is very well simulated but the wind speed is constantly overestimated, even at $10 \mathrm{~m}$. At the beginning of the simulation period, the simulated $10 \mathrm{~m}$ wind direction is more perturbed than the observed wind direction. It fluctuates in the range of the observed direction and $45 \mathrm{~min}$ previous to the LLW the numerical model anticipated the wind direction changes, varying from west to north. Both the overestimation of the wind speed and the difference in wind direction can be explained by the fact that the chosen grid point (the nearest) in the numerical simulation is south of the airport in a grid with only sea roughness. The nearest point above land was located in the Var valley and was even more perturbed by the complex orography. The wind over the sea is slightly stronger than over land due to lower 


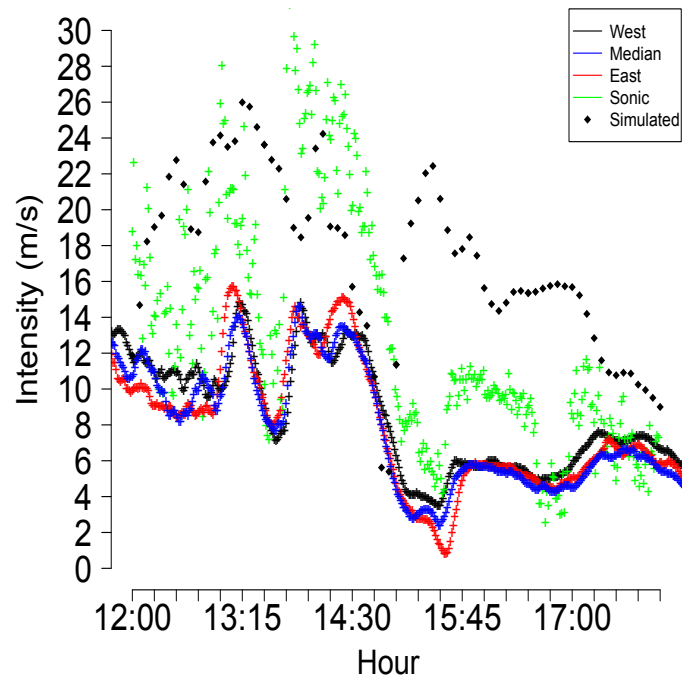

(a)

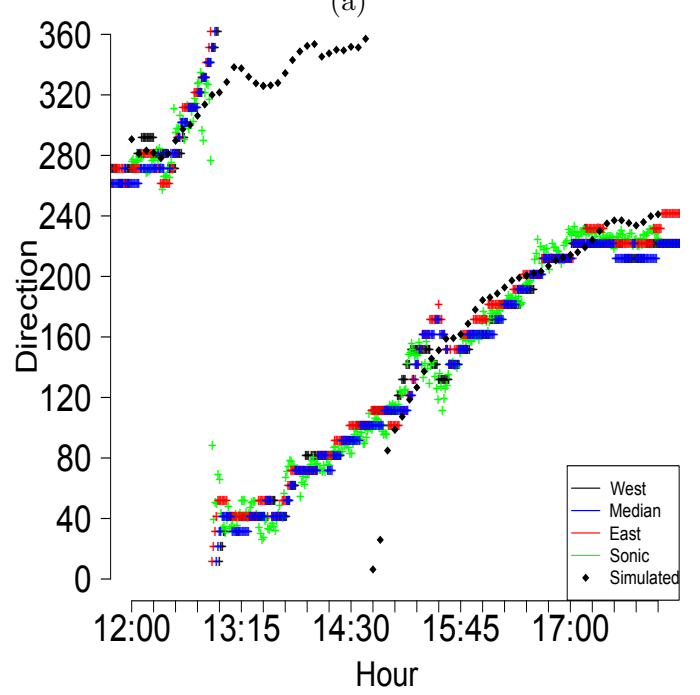

(b)

Fig. 14. Time series: each minute of $10 \mathrm{~m}$ wind intensity (a) and direction (b) between 12:00 UTC and 18:00 UTC on 24 March 2009 observed by the four airport anemometers and simulated by MesoNH.

surface roughness values. The Var valley breeze extension reaches the point at the beginning of the simulation, then a wind similar to the wind observed to the east is simulated at 07:30. The LLW seems to be anticipated during the low intensity period when the valley breeze regains in extension and a northerly wind is simulated at this point.

The LLW is simulated a quarter of an hour later than observed but a change of $120^{\circ}$ occurs in $5 \mathrm{~min}$ in the simulation, whereas it takes $15 \mathrm{~min}$ for the observed wind direction to change similarly. For that reason, observed and simulated winds fit very rapidly after the LLW.

In the same way, the $2 \mathrm{~m}$ temperature is well represented (not shown). Both the magnitude and the position of the $2 \mathrm{~m}$

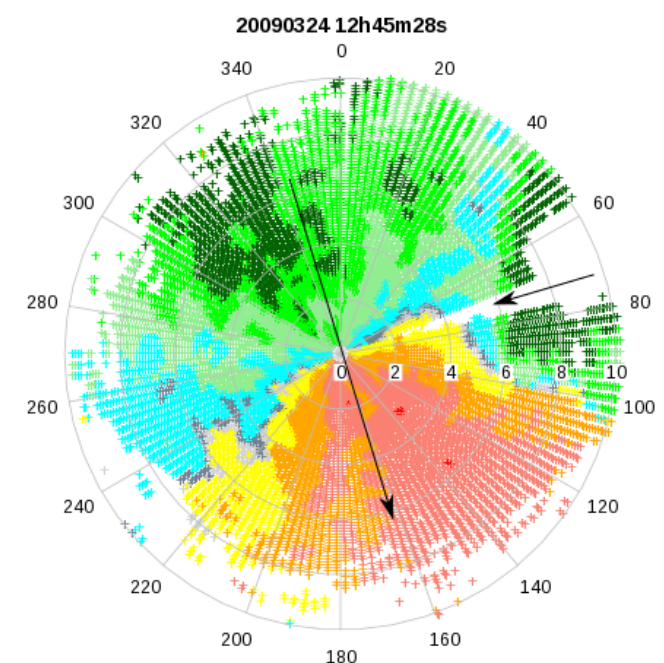

(a)

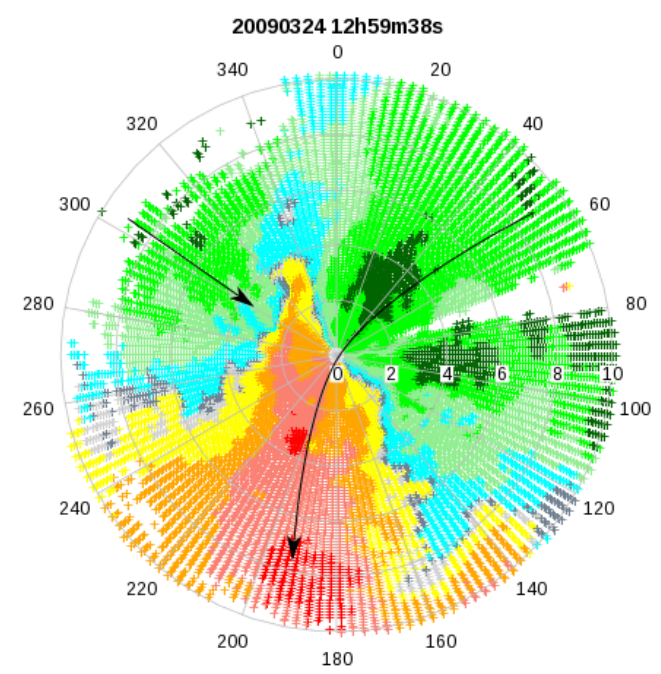

(b)

Radial speed range

$-20=-15=-10=-5 \quad \square-1 \quad=1 \quad 5 \quad=10 \quad=15 \quad=20$

Fig. 15. Radial wind intensity: lidar scan at 13:00 UTC (a), equivalent Meso-NH simulated scan at 15:00 UTC (b).

temperature gradient in the Nice area are well captured by the numerical simulation during the entire simulation compared to the ground measurement station network. Since the temperature gradient is related to the position of the LLW as presented in the case description, it confirms that the regional structure of the LLW is well simulated.

At 09:30 a second wind direction change occurs over the Nice airport as shown on the time series (Fig. 15). Figure 16 presents the wind lidar scans at $2^{\circ}$ of elevation at 19:30 and 10:00 UTC as well as the equivalent simulated scans. The simulation reproduces the wind structure in a satisfactory way. There is a time lag at the beginning of the second LLW. Indeed, as seen previously, the wind speed is stronger in the 


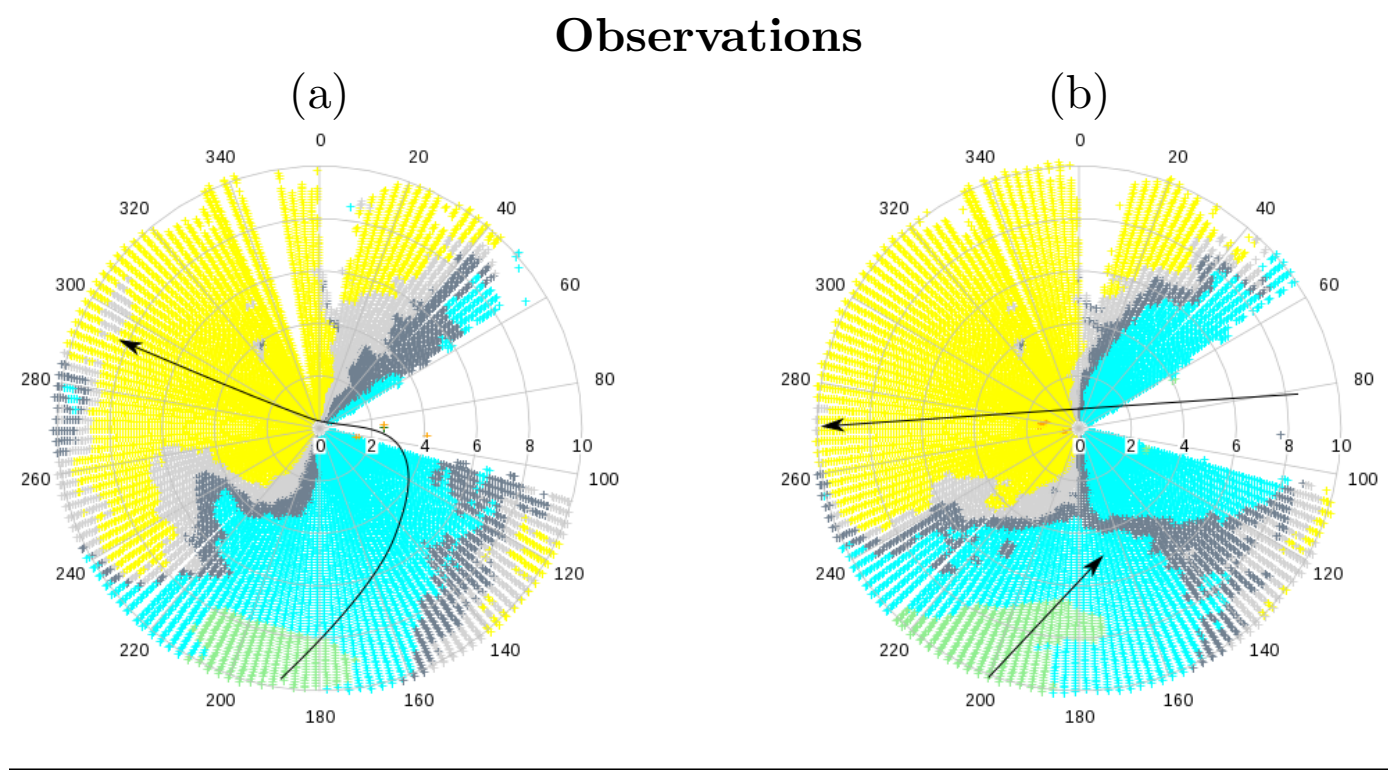

\section{Simulation}

(c)

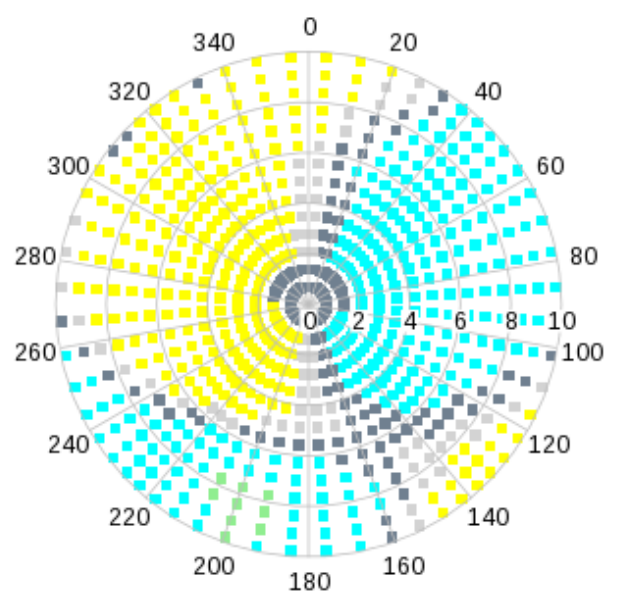

(d)

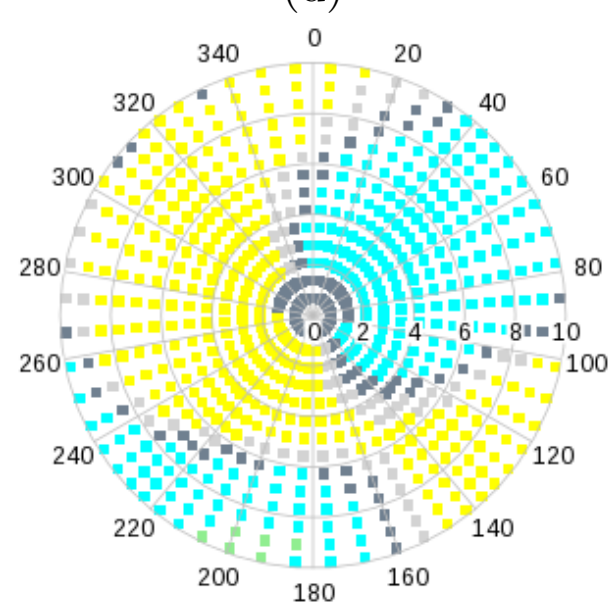

Radial speed range

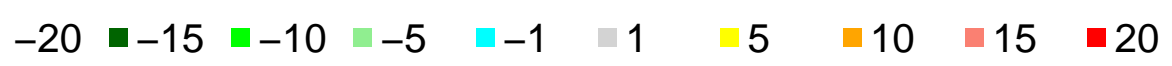

Fig. 16. Lidar scans at $2^{\circ}$ at 09:20 (a) and 10:00 (b) on 27 March 2009 and Meso-NH simulated equivalent at 9:30 (c) and 10:00 (d).

simulation than measured by the anemometer measurements and the 09:30 simulated scan is similar to the observed one at 10:00. The local wind direction and speed are well simulated but the wind structure is anticipated in the simulation.

The advantage of a numerical simulation is the large amount of regional information available. Vertical crosssections of vertical velocity and potential temperature are presented in Fig. 17. The vertical wind component at 08:00 and 10:00 is presented in the left column and the temperature superimposed on the wind intensity in the right column.
Waves are present in the lee of the mountains, above the Nice airport from the beginning of the simulation. These waves intensify once at 08:00 and strengthen a second time at 10:00. At that time the wind oscillations appear upwind of the mountains compared to the waves at 08:00. The vertical component oscillation is coupled with a similar oscillation of potential temperature in the lower layer above the mountains. The strong vertical wind component in the lee of the mountain seems to be maintained in altitude even more after the reinforcement at 10:00. The oscillations are probably 
(a) Vertical wind speed $\left(\mathrm{m} \cdot \mathrm{s}^{-1}\right)$
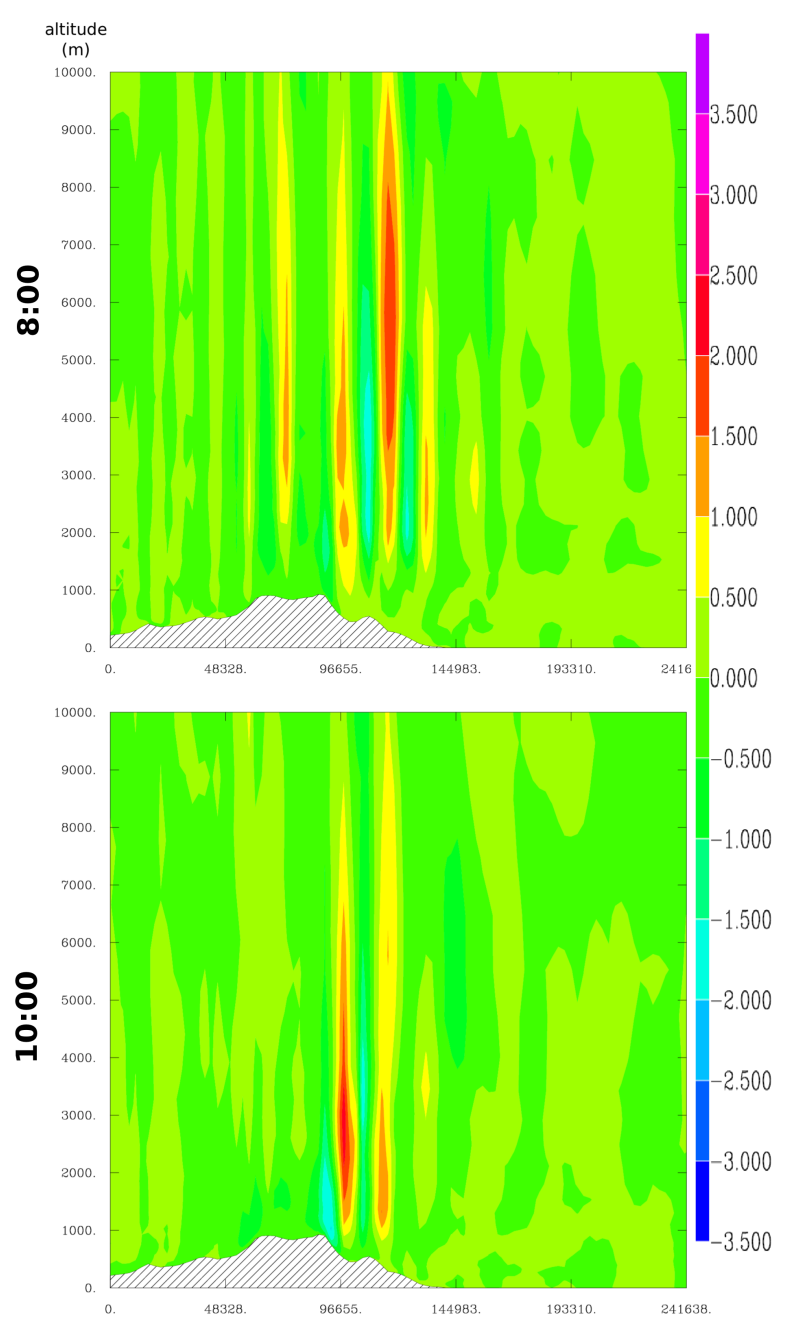

(b) Wind intensity $\left(\mathrm{m} \cdot \mathrm{s}^{-1}\right)$

Potential temperature $(\mathrm{K})$
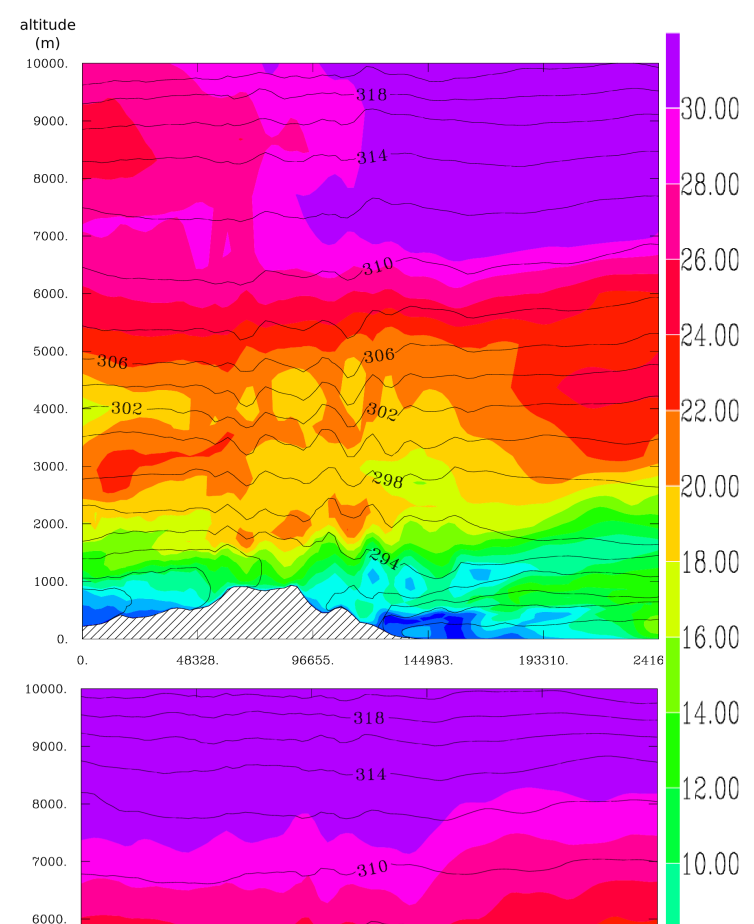

6000. 8.000
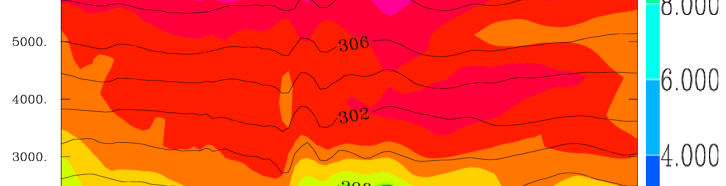
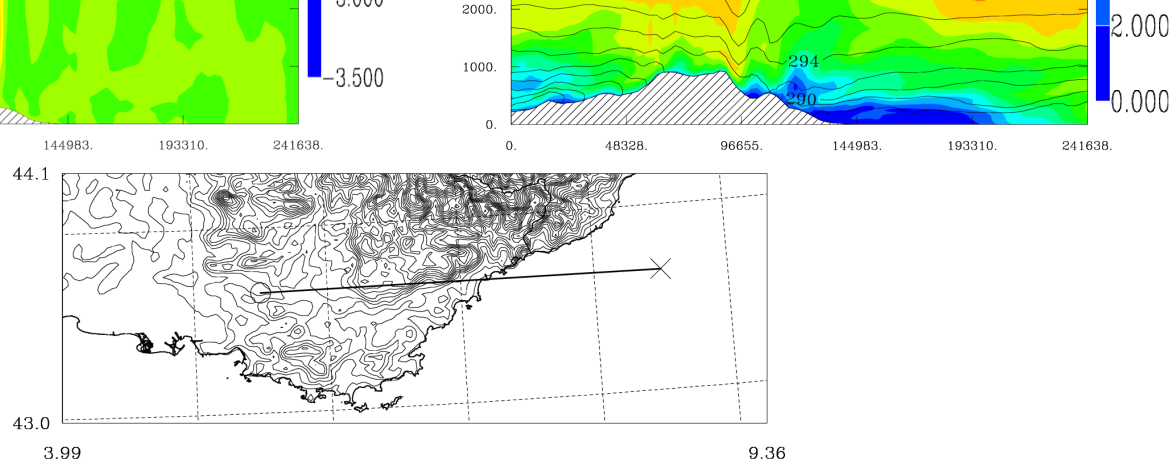

Fig. 17. Cross section of vertical wind speed (a) and potential temperature isolines superimposed on wind intensity (b) from ground to $10 \mathrm{~km}$ high directed from west to east through Nice on 27 March 2009 at 08:00 (up) and 10:00 UTC (bottom).

absorbed by the cold air mass as stated in Jiang et al. (2006) and as a counterpart they press the cold air to the ground. The cold air mass in the boundary layer acts as a shield preventing the synoptic wind to reach the Nice airport and it maintains the easterly wind. The same kind of cold pool and waves in the lee of the mountains were observed on another similar LLW event over Nice in 2005.

\section{Conclusions}

This paper is a study of two different horizontal LLW events taking place over the Nice airport. This airport is mostly concerned with horizontal wind shears and no LLW dedicated systems are installed on the runways. In 2009 a wind lidar campaign took place at the Nice airport, providing a very useful and complete dataset. We carried numerical simulations for two particular LLW events in the best configuration 
that could be obtained in near real time to test the ability of the numerical model to predict these hazardous events. The simulations were carried out at high resolution $(2.5 \mathrm{~km})$ on a domain covering the entirety of France to reproduce the synoptic situation. A higher resolution $(500 \mathrm{~m})$ nested domain was also run over the airport area but did not provide real improvements on the LLW timing and position compared to the $2.5 \mathrm{~km}$ domain presented in this paper. However, orographic effects (i.e. valley breezes, hill effects) were greatly improved and could lead to a better prediction of vertical wind shears or local turbulence.

In the first case, called "crossing the Alps", the LLW was due to large-scale conditions. The LLW was not predicted at the right place and time due to the misrepresentation of these conditions. In that case one way to improve the LLW position would be to constrain the simulation more regularly towards large-scale conditions through analysis nudging at each time step for example.

For the second LLW event ("vortex case"), the LLW generation is more related to regional effect (orography, breezes...). The model successfully anticipates $1.5 \mathrm{~h}$ before the wind direction and intensity change. For that reason it has been used to complement measurements. Waves were observed in the lee of the southern part of the Alps. During another LLW event over the Nice airport, more intense wave structures were simulated and the LLW was more rapid.

A stable lower layer in the Genoa gulf and a strong synoptic wind are mandatory to generate a LLW over the Nice area in both cases. The Froude number upwind of the Alps in both LLW events was found close to 1 . These three characteristics have to be present for a LLW to occur over the Nice airport. To further improve the timing, position and structure prediction of the LLW event, local measurements at high-frequency and resolution could be assimilated in the model (Calpini et al., 2011). To take into account the rapidly changing wind field observed by a wind lidar as many scans as possible should be assimilated. For this purpose an enhanced nudging technique (Back and Forth Nudging, Auroux and Blum, 2005) was developed into Meso-NH (Boilley and Mahfouf, 2012). The use of the high-resolution domain $(500 \mathrm{~m})$ would then become mandatory.

To predict wind shears over the Nice airport, a combination of numerical predictions and observations is necessary. Numerical models are able to predict and generate a warning about LLW appearance in the next $6 \mathrm{~h}$. However, the time and position of the wind change are not well captured and must be complemented by local measurements to keep watch on the position of the LLW. More upwind sensors could also be installed to further anticipate the arrival of a wind shear on the Nice airport area.

Acknowledgement. We would like to acknowledge all the Meso-NH team for their help on numerical setup. The support of Christine Lac and Valéry Masson during the course of this study has been particularly appreciated. Thanks to Olivier Caumont for developing the wind lidar simulator. We acknowledge Eric Schwartz for sharing his experience, data and sense of humour about these local "wind reversal" events. Thanks to Lucien Wald who spent time reading this paper with a critical eye.

Edited by: A. Mugnai

Reviewed by: two anonymous referees

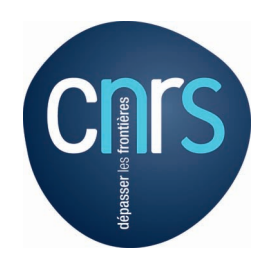

The publication of this article is financed by CNRS-INSU.

\section{References}

Auroux, D. and Blum, J.: Back and forth nudging algorithm for data assimilation problems, C. R. Acad. Sci. Ser. I, 340, 873$878,2005$.

Belamari, S.: Report on uncertainty estimates of an optimal bulk formulation for surface turbulent fluxes, Technical report, MERSEA IP deliverable D4.1.2, 29, 2005.

Boilley, A. and Mahfouf, J.-F.: Assimilation of low-level wind in a high-resolution mesoscale model using the back and forth nudging algorithm, Tellus A, 64, 18697, doi:10.3402/tellusa.v64i0.18697, 2012.

Bougeault, P. and Lacarrère, P.: Parametrization of orographic induced turbulence in a mesobeta scale model, Mon. Weather Rev., 117, 1872-1890, 1989.

Bubnova, R., Hello, G., Bernard, P., and Geleyn, J.-F.: Integration of the fully elastic equations cast in the hydrostaticpressure terrain-following coordinate in the framework of the ARPEGE/ALADIN NWP system, Mon. Weather Rev., 123, 515-535, 1995.

Calpini, B., Ruffieux, D., Bettems, J.-M., Hug, C., Huguenin, P., Isaak, H.-P., Kaufmann, P., Maier, O., and Steiner, P.: Groundbased remote sensing profiling and numerical weather prediction model to manage nuclear power plants meteorological surveillance in Switzerland, Atmos. Meas. Tech., 4, 1617-1625, doi:10.5194/amt-4-1617-2011, 2011.

Caumont, O., Ducrocq, V., Delrieu, G., Gosset, M., Pinty, J.-P., du Chatelet, J. P., Andrieu, H., Lemaitre, Y., and Scialom, G.: A radar simulator for high-resolution nonhydrostatic models, J. Atmos. Oceanic Technol., 23, 1049-1067, 2006.

Chan, P. W.: An event of tail strike of an aircraft due to terraininduced wind shear at the Hong Kong International Airport, Meteor. Appl., 19, 325-333, doi:10.1002/met.264, 2012.

Fischer, C., Montmerle, T., Berre, L., Auger, L., and Stefanescu, S. E.: An overview of the variational assimilation in the ALADIN/France numerical weather-prediction system, Q. J. Roy. Meteor. Soc., 131, 3477-3492, 2005.

Fouquart, Y. and Bonnel, B.: Computations of solar heating of the earth's atmosphere: a new parameterization, Beitr. Phys. Atmosph., 53, 35-62, 1980.

Fujita, T.: The Downburst: Microburst and Macroburst, University of Chicago press, 1986. 
Gal-Chen, T. and Sommerville, C. J.: On the use of a coordinate transformation for the solution of the Navier-Stokes equation, J. Comput. Phys., 17, 209-228, 1975.

Gohm, A., Zängl, G., and Mayr, G. J.: South Foehn in the Wipp Valley on 24 October 1999 (MAP IOP 10): Verification of high-resolution numerical simulations with observations, Mon. Weather Rev., 132, 78-102, 2004.

Jiang, Q., Doyle, J. D., and Smith, R. B.: Interaction between trapped waves and boundary layers, J. Atmos. Sci., 63, 617-633, 2006.

Lafore, J. P., Stein, J., Asencio, N., Bougeault, P., Ducrocq, V., Duron, J., Fischer, C., Héreil, P., Mascart, P., Masson, V., Pinty, J. P., Redelsperger, J. L., Richard, E., and Vilà-Guerau de Arellano, J.: The Meso-NH atmospheric simulation system. Part I: adiabatic formulation and control simulations, Ann. Geophys., 16, 90-109, doi:10.1007/s00585-997-0090-6, 1998.

Masson, V.: A physically-based scheme for the urban energy budget in atmospheric models, Bound. Lay. Meteorol., 94, 357-397, 2000.

Michelson, M., Shrader, W., and Wieler, J.: Terminal doppler weather radar, Microwave J., 33, 139-148, 1990.

Mlawer, E. J., Taubman, S. J., Brown, P., Iacono, M., and Clough, S.: Radiative transfer for inhomogeneous atmospheres: RRTM, a validated correlated-k model for the longwave, J. Geophys. Res., 102D, 16663-16682, 1997.

Noilhan, J. and Planton, S.: A simple parameterization of land surface process for meteorological models, Mon. Weather Rev., 117, 536-549, 1989.

Ólafsson, H. and Bougeault, P.: Nonlinear flow past an elliptic mountain ridge, J. Atmos. Sci., 53, 2465-2489, 1996.
Pinty, J.-P. and Jabouille, P.: A mixed-phase cloud parameterization for use in mesoscale non-hydrostatic model: simulations of a squall line and of orographic precipitations, in: 14th Conference on Planned and Inadvertent Weather Modification, Everett, WA, 1998.

Politovich, M., Goodrich, R. K., Morse, C. S., Yates, A., Barron, R., and Cohn, S.: The Juneau terrain-induced turbulence alert system, Bull. Am. Meteor. Soc., 92, 299-313, 2011.

Proctor, F.: Numerical simulations of an isolated microburst, part I: dynamics and structure, J. Atmos. Sci., 45, 3137-3160, 1988.

Seity, Y., Brousseau, P., Malardel, S., Hello, G., Bénard, P., Bouttier, F., Lac, C. and Masson, V.: The AROME-France convective scale operational model, Mon. Weather Rev., 139, 976-991, 2011.

Shun, C. M. and Chan, P. W.: Applications of an infrared doppler lidar in detection of wind shear, J. Atmos. Oceanic Technol., 25, 637-655, 2008.

Soffer, E. P.: Establishment criteria for integrated wind shear detection systems: Low-Level Wind Shear Alert System (LLWAS), Terminal Doppler Weather Radar (TDWR), and modified airport surveillance radar, US Department of Transportation, Federal Aviation Administration, Office of Aviation Policy and Plans FAA-APO-90-13, 1990.

Wilson, J. W., Roberts, R. D., Kessinger, C., and McCarthy, J.: Microburst wind structure and evaluation of Doppler radar for airport wind shear detection, J. Climate Appl. Meteor., 23, 898-915, 1984. 